\title{
Physicochemical Properties of Phosphatidylcholine (PC) Monolayers with Different Alkyl Chains, at the Air/Water Interface
}

\author{
Heejung Yun, Young-Wook Choi, Nam Jeong Kim, ${ }^{*}$ and Daewon Sohn* \\ Depatment of Chemistn: Handang liniversity, 17 Haengdong Dong, Seod 133-791, Korea

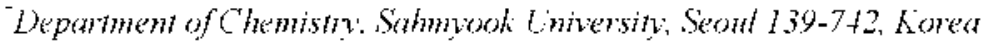 \\ Received September 13,2002
}

\begin{abstract}
Phy sicochemical properties ol a series of PC monolayers with dillerent alkyl chains $(\mathrm{C} 24, \mathrm{C} 20, \mathrm{C} 16$, and $\mathrm{C} 8)$, at the andwater interlace nere investigated. The surlace presiure is inlluened mainly by the hydrophobicity of the PC's, wheh is conlimed by the eurve shape and the on-set value of $\pi$-A isothems at the air/water interlace by increasing the number of alkyl chain. The on-sel values of surlace pressure were $125 A^{2} /$ molecule for

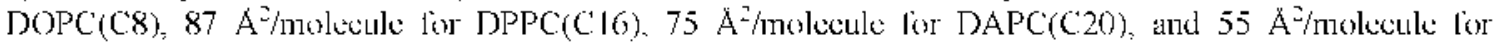
DI.PC (C24), respectively. The orientations ol alkyl chains at the air/water interlace are closely connected with the rigidity of the monolayers, and it was conlimed by the tendeney of monolayer thickness in ellipsometry data. The temperature dependence of a series of PCs shows that the surlace pressure decreases by increasing temperature, because the lomger the alkyl chain lenglh, the larger the hydrophobic interaction in surlace prosiure. The temperalure elfects and the contomational changes of unsaturated and salurated PCs were confimed by the computer simulation study of the eis-trans transition with POPC and DPPC(C 16$)$. The cistrans conlomeational energy dillerence of POPC is $62.06 \mathrm{keal} / \mathrm{mol}$ and that of $\mathrm{DPPC}(\mathrm{C} / 6)$ is $6.75 \mathrm{kcal} / \mathrm{mol}$. Dut to the high contomational energy banier ol POPC, phase transition ol $\mathrm{POPC}$ is limited in conpantison with DPPC. (CI6)
\end{abstract}

Key Words : 1'hosphatidylcholine, Langmuir-Blodgett monolayer, lyydrophobicity; Unsaturated phosphatidvlcholine

\section{Introduction}

Phospholipids are major components of biological membranes and have gained current interest in many ficlds such as biochemistry. chemistry. and polymer science. Recently. molecular films of biomolecules have received increased attention because of their potential applications in biological sensors and oller applications in materials science.

As a model system of biological membranc. LangmuirBlodget films have becn inestigatcd by many rescarcliers for many years. ${ }^{1-3}$ The characteristic propertics of molecules at the air/water interface are gencrally claracterized by $\pi$-A isotherms ${ }^{4-5}$ which are cnicial in obtaining a proper understanding of what is occurring at the molccular level. For example. Gibbs clasticity of a monolayer is deconnined from the slope of the $\pi$-A isotherms. It is also known that the shapes of the $\pi$-A isolherms depend on many variations including temperature. "impuritics. " and specd of compression. By simply analyzing the $\pi$-A isotherms. the process of monolayer fommation and the plysical propertics of the single molecule can be inferred from the shape and slope of the $\pi$-A isolhenns. "2 The combined effects of lydropliobic and lyydrophilic interactions are two most important noncovalent interactions dominated in the phospliolipid bilayer structure in solution as well. ${ }^{13}$

The phospholipids were influenced by crystallization of

"Comesponding author. Phone: +82-2-2290-0933: Fax: +82-22299-0762: L-mail: dsohn à ihanyang.ac.kr fatty acids. so that they could be uscd as bioactive componenis in vivo. ${ }^{1.1 .15}$ Especially. PC (phosphatidy lcholinc) phospholipids have gained the interest because of its phanmaccutical usefulness to promote netabolism through the cell membranc. For cxample. PCs with short clain. C6-C8 atoms. are cndowed with delergent-like propertics. These compounds form micelle rather than bilayer when dispersed in water with a relatively ligh critical micelle concentration (CMC). ${ }^{16}$ They have becn applicd successfully in the solubilization of biological membranes and the reconstitution of membrane proteins into simple. Well-defined membranc systems (protcoliposomes). ${ }^{17}$ For another example to facilitate breathing. it is required that surface tension at the airalycolar interface in the mammalian lung be reduced to near zero from the nommal valuc of $72 \mathrm{mN} / \mathrm{m}$ at the air/water interface. ${ }^{18}$ fn trito. surface tension is regulated by pulmonary surfactant. a lipid-prolein complex. Deficiency of this matcrial causes respiratory distress syndrome (RDS) ir premature infants. " and has also becn implicated in the adult rersion of RDS. which is often Irauma-related. ${ }^{2 !}$ The gross composition of typical surfactant isolates is $95 \%$ lipid and $5 \%$ protein by weight. with the main lipid classes being the phosplocholines and phosphoglycerols. Pulmonary lung surfactant is approximately $50 \%$ 1.2-dipalmitoyl-sn-glyccro3-plosphocholine by wcight. DPPC(C16) (1.2-dipalmitoylsn-glycero-3-phosphocholine) is generally accepled as being the lipid responsible for generating a near-zero surface tension at the interface during compression." The two saturated alkyl clains cnable the lipid to form a tightly packed mono- 
laỵer which can generate low surface tension without collapsing. The unsaturated PC lipids might be important in the fomation of a lipid reservoir, in the initial adsorption of lipids to the interface or in the regulation of surface tension during the respiratory cycle. Other functions in intracellular events, such as lamellar body assembly, transport or secretion. are also possible. ${ }^{22}$ These biophysical approaches are also necessary for the rational design of exogenous surfactants for therapeutic purpose

Although many studies with these lipids have been performed because of their various applications. there are lacks of studies for the saturated derivatives $\mathrm{PC}$ and the unsaturated $\mathrm{PC}$ to provide the influence of the hydrophobic forces of phosplatidylcholine on the self assembled structure.

In this study: the physicochemical properties of PCs (C8. $\mathrm{C} 16 . \mathrm{C} 20$ and $\mathrm{C} 24)$ monolayers. at the air/water interface were studied by Langmuir-Blodgett teclunique. The conformational changes of unsaturated POPC and saturated DPPC (C16) by the increase of surface pressure at the air/water interface were observed by $\pi$-A isothemis and were confimm- ed by the computer simulation with CHARMM.

\section{Materials and Experimental Methods}

Materials. The phospholipids used in this study were 1.2dioctanoyl-sn-glycerol-3-phosphocholine (DOPC $(\mathrm{C} 8)$ ), 1 , 2-dipalmitoyl-sn-glycero-3-phosphocholine (DPPC(C16)), 1.2-diarachidoyl-sn-glycero-3-phosphocholine (DAPC(C20)). 1.2-dilignoceroyl-sn-glycero-3-ph-osphocholine (DLPC(C24)). and 1-palmitoy 1-2-oleoyl-sn-glycero-3-phosphocholine (POPC). all obtained from Avanti Polar Lipids, Inc.. Alabaster. AL. Their chemical structures are in Figure 1. They all had purities of $99 \%$ and were used as received. Spectroscopic grade clloroform (Aldrich) was used as the spreading solvent. Water was prepared using a Millipore Milli-Q sy stem. which had a resistivity of $>18.2 \mathrm{MS}^{-1}$.

\section{Experimental Methods.}

Langmuir-Blodgett technique: An automatically controlled Langmuir film balance KSV3000 (KSV Instruments Ltd. Finland) equipped with a platinum Wilhelıny plate. was used to obtain the surface pressure-area $(\pi$-A) isotherms of

(a)

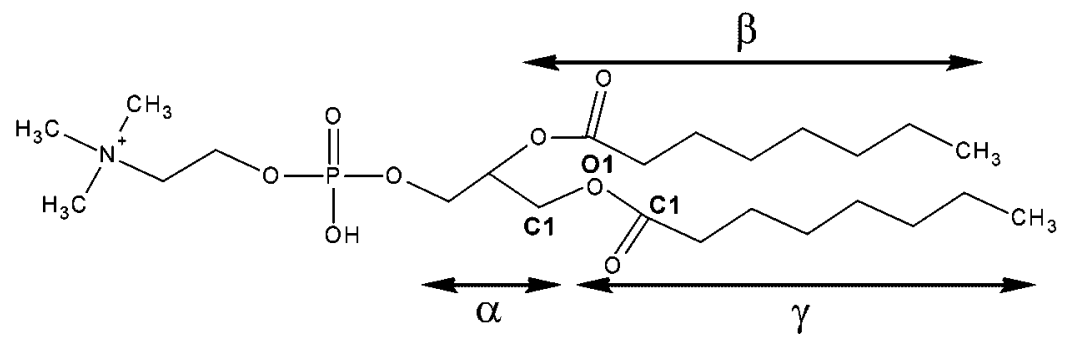

(b)<smiles>CCCCCCCCCCCCCCCC(=O)OCC(COP(=O)(O)OCC[N+](C)(C)C)OC(=O)CCCCCCCCCCCCC</smiles>

(c)<smiles>CCCCCCCCCCCCCCCCCCCCCCCCCCCCCCCC(=O)OCC(COP(=O)(O)OCC[N+](C)(C)C)OC(=O)CCCCCCCCC</smiles>

(d)<smiles>CCCCCCCCCCCCCCCCCCCCCCCCCCCCCCCCCCCCCCCC(=O)OCC(COP(=O)(O)OCC[N+](C)(C)C)OC(=O)CCCCCCCCCC</smiles>

(e)<smiles>CCCCCCCC=CCCCCCCCCCCCCC(=O)OCC(COP(=O)(O)OCC[N+](C)(C)C)OC(=O)CCCCCCCCCC</smiles>

Figure 1. The chemical stucture of (a) DOPC(C8), (b) DPPC(C 16), (c) DAPC(C20), (d) DLPC(C24), (c) POPC. 
monolayers at the air/water interface. For all experiments, the trough was filled with purified water as the subphase. and the temperature was maintained by extemal water bath circulation. The air/water interface could be compressed and expanded symmetrically with two teflon barriers at a desired rate. The cleanliness of the trough and subphase was ensured before each experiment by aspirating the surface of subphase. When the surface pressure fluctuation was found to be less than $0.1 \mathrm{mN} / \mathrm{m}$ during the compression cycle. a sample containing monolayer-forming materials was spread on the subphase surface by using a microsy ringe (Hamilton Co. USA). Ten minutes were allowed for solvent evaporation and monolayer equilibration before an experiment was started. After allowing for the solvent to evaporate. the monolayer at the air/water interface was continuously compressed at a rate of $7.5 \mathrm{~cm}^{2} / \mathrm{nin}$ to obtain the $\pi$-A isothenns. As a monolayer was compressed to be in a condensed phase. the isotherm generally exlibited a sharp collapse followed by an abnornal change of surface pressure upon firther compression. which was referred to as the collapse point of the monolayer under the given experimental condition.

Ellipsometry: Auto EL nulling ellipsometer (Rudolph scientific) was used to measure the thickness of LB monolayer. The compensator is set at an azimuth angle of $70^{\circ}$ to sample surface. The optical parameter $\Delta$ and $\Psi$ were used for calculating apparent thickness of film material. Average values from 5 measurements on $\mathrm{Si} / \mathrm{SiO}_{2}$ served as reference. and the arerage value for film thickness obtains from 6 measurements on each sample.

\section{Results and Discussion}

$\pi$-A isotherms of $\mathrm{PC}$ monolayers with different length of alkyl chain. Figure 2 shows the $\pi$-A isotherms for the pure DOPC(C8). DPPC $(\mathrm{C} 16)$. DAPC (C20). and DLPC (C24) at $25^{\circ} \mathrm{C}$. As the length of alkyl chain increase, the onset values of surface pressure shift toward lower area per molecule (Am). The on-set values of surface pressure were $125 \mathrm{~A}^{2} /$ molecule for DOPC(C8), $87 \mathrm{~A}^{2} /$ molecule for DPPC (C16). $75 \AA \%$ molecule for DAPC(C20), and $55 \AA \%$ molecule for $\mathrm{DLPC}(\mathrm{C} 2+)$, respectively. The $\pi$-A isotherms show that PCs with short alkyl chain have smooth increase of surface pressure. which could be explained as the monolayer fluidity of $\mathrm{DOPC}(\mathrm{C} 8)$. because they are dominated by the weak order of its relatively short hydrocarbon chains. In contrast. PCs with long alkvl chains have stiff increase of surface pressure. The monolayers of DAPC $(\mathrm{C} 20)$ and DLPC $(\mathrm{C} 2 t)$ are rather rigid than those of short alkyl chains because of condense order of its relatively long hydrocarbon chains. Orientation of alkyl chains at the air/water interface is the main factor for the rigidity of monolayers. Orientation of the alkyl chains of long PCs is rather horizontal with the respect to the surface nomal. which represents that DAPC $(\mathrm{C} 20)$ and $\mathrm{DLPC}(\mathrm{C} 2+)$ are arranged vertically at the air/water surface of large Am. and it is confirmed by ellipsometry data as in Figure 3 .

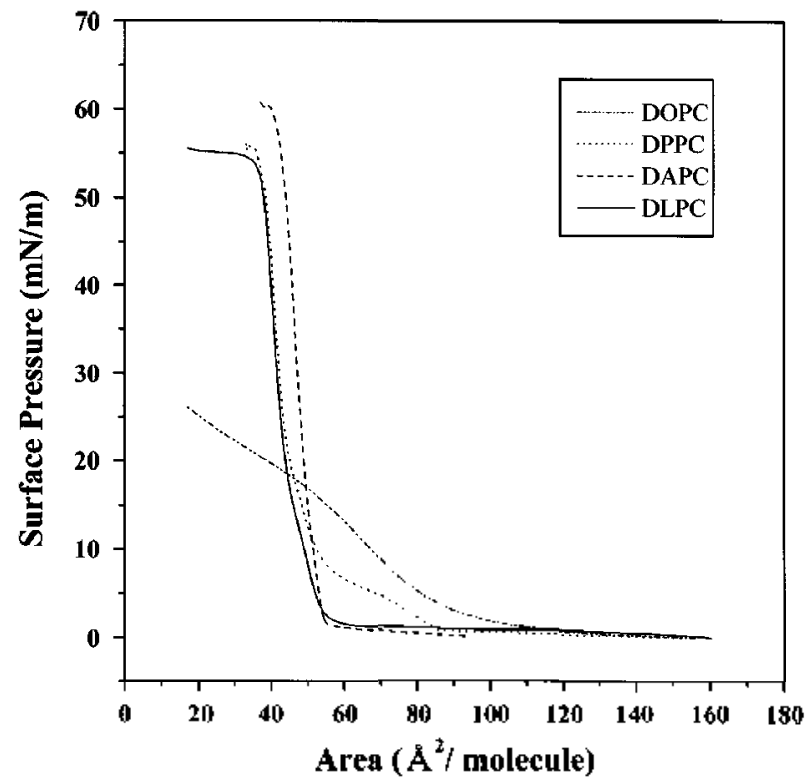

Figure 2. The $\pi-\Lambda$ isotherms of $P C s$ with ditferent alkyl chain longths, DOPC (C8), LPPC (C16), DAPC (C20), and DLPC (C24), at $25^{\circ} \mathrm{C}$.

Figure 3(a) shows the $\pi$-A isotherm and the monolayer thickness of DOPC(C8) depending on the area per molecules. We observed smooth increase of film thickness through the decreased surface area. in which the alky'l chains are amranged slowly and vertically to the plane of subphase surface. Monolayer thickness was $5 \mathrm{~A}$ at the $160 \mathrm{~A}^{2} /$ molecule and change to $9 \mathrm{~A}$ at the $20 \mathrm{~A}^{2} /$ molecule. In contrast. Figure $3(\mathrm{c})$ of $\mathrm{DLPC}(\mathrm{C} 2+)$ shows stiff increase of monolayer thickness and surface pressure due to the large hydrophobicity of long alkyl chains. Figure 3(b) is the $\pi$-A isotherm and the monolayer thickness of $\mathrm{DPPC}(\mathrm{C} 16)$ which has two transitions: a sinall transition at around $80 \mathrm{~A} /$ molecule and a stiff transition at around $50 \mathrm{~A} /$ molecule. A small transition is generally known as the liquid condensed state transition in which the molecules are closed packed with the hydrocarbon chains in a more ordered state. Relatively long alkyl chains of $\mathrm{DLPC}(\mathrm{C} 24)$ generate the strong hydrophobic interactions between the hydrocarbons, but short chains of DOPC(C8) make relatively flexible and weak interaction between the chains. The PCs having 16 hydrocarbons have competition between the hydrophobic intermolecular interaction and the chain flexibility:

Temperature effects of PC monolayers with different alkyl chain lengths. Figure $t(a)$ and $t(b)$ show the temperature dependent $\pi$-A isotherms of $\mathrm{DOPC}(\mathrm{C} 8)$ and $\mathrm{DPPC}(\mathrm{Cl} 6)$, respectively. In Figure $t(\mathrm{a})$. by increasing temperature, the surface pressure decreases. At $60 \mathrm{~A}^{2} /$ molecule. the surface pressure values have $17 \mathrm{mN} / \mathrm{m}$ for 10 "C. $13 \mathrm{mN} / \mathrm{m}$ for $20^{\circ} \mathrm{C} .9 \mathrm{mN} / \mathrm{m}$ for $30{ }^{\circ} \mathrm{C} 5 \mathrm{mN} / \mathrm{m}$ for 40 "C. It explains that $\pi$-A isotherms are dominated by the combined effect of hydrophobicity of alkyl chains and interaction between hydrophilic parts and aqueous subphase. The isotherm of $\mathrm{DOPC}(\mathrm{C} 8)$ is dominated by the interaction between the hydrophilic part and the aqueous surface 

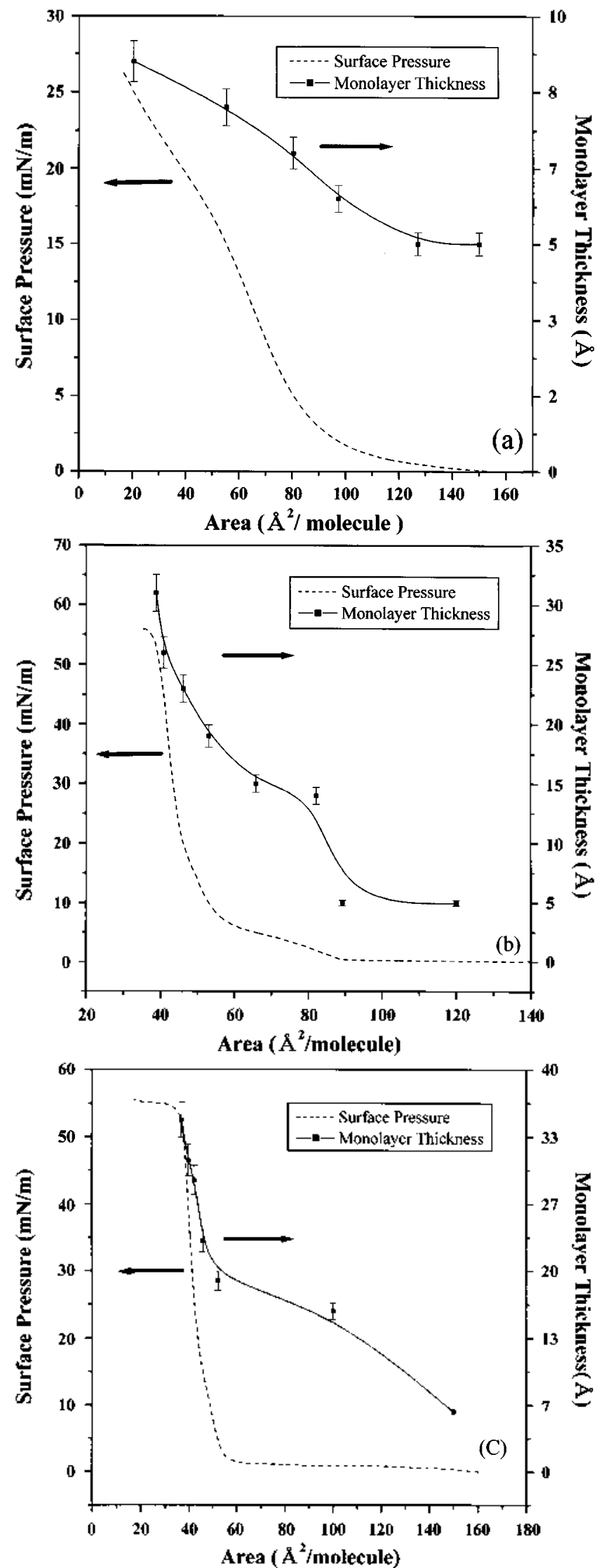

Figure 3. The $\pi$-A isotherms (-) and monolaver thickness is. area per molecule (Am) curves ( a ) of (a) DOPC(C8) (b) DPPC(C 16). and (c) DI.PC(C24), at the air-water interface. The monolayer thickless was measured by elljpsometer. because of relatively short alkyl chain. So. by increasing temperature. hydrogen bonding between head group and aqueous phase is broken. and the surface pressure through full range is reduced. By contraries, in Figure $4(\mathrm{~b})$, the higher temperature. the larger surface pressure, at $50 \mathrm{~A}^{2} /$ molecule. and the surface pressure values have $0.2 \mathrm{mN} / \mathrm{m}$ for $10^{\circ} \mathrm{C} .7 .5 \mathrm{mN} / \mathrm{m}$ for $20^{\circ} \mathrm{C} .25 \mathrm{mN} / \mathrm{m}$ for $30{ }^{\circ} \mathrm{C}$. and 36.5 $\mathrm{mN} / \mathrm{m}$ for $40{ }^{\circ} \mathrm{C}$. It could explain that the isotherms of $\mathrm{DPPC}(\mathrm{Cl6})$ are controlled by the hydrophobicity of alksl chains. So. by increasing temperature, the thermal motion of alkyl chains is increased. and the surface pressure is increased. By all accounts, with expansion of alkyl chain length. the predominance of hydrophobic interaction in surface pressure is getting bigger. The longer hydrocarbons in $\mathrm{DAPC}(\mathrm{C} 20)$ and DLPC(C24) make strong chain interactions, so they do
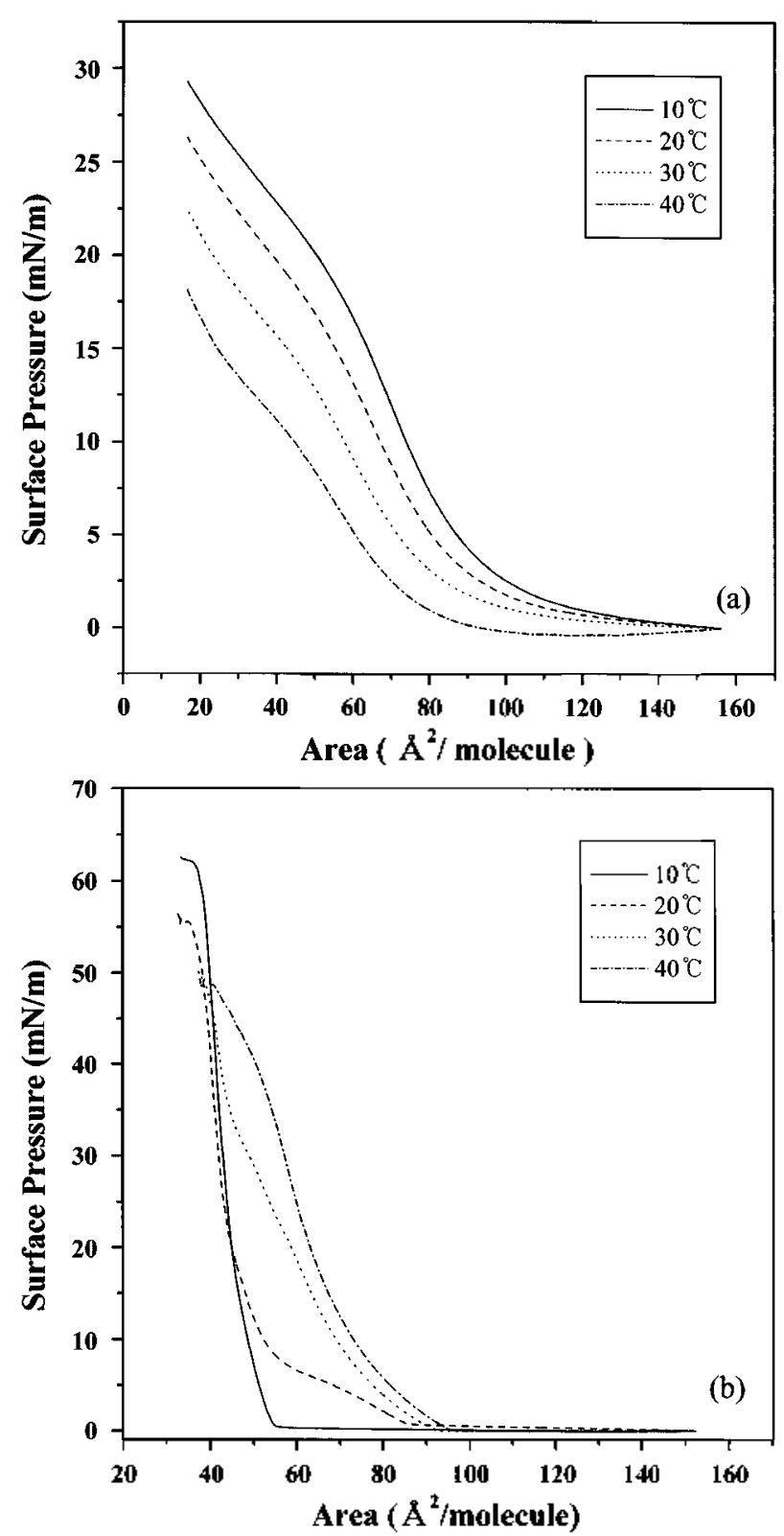

Figure 4 . The $\pi-A$ isothenns of (a) DOPC(C8), (b) DPPC(C16). (c) DAPC(C26). (d) DLPC(C24) and (e) POPC with various lemperalures at the air/waler interface. 


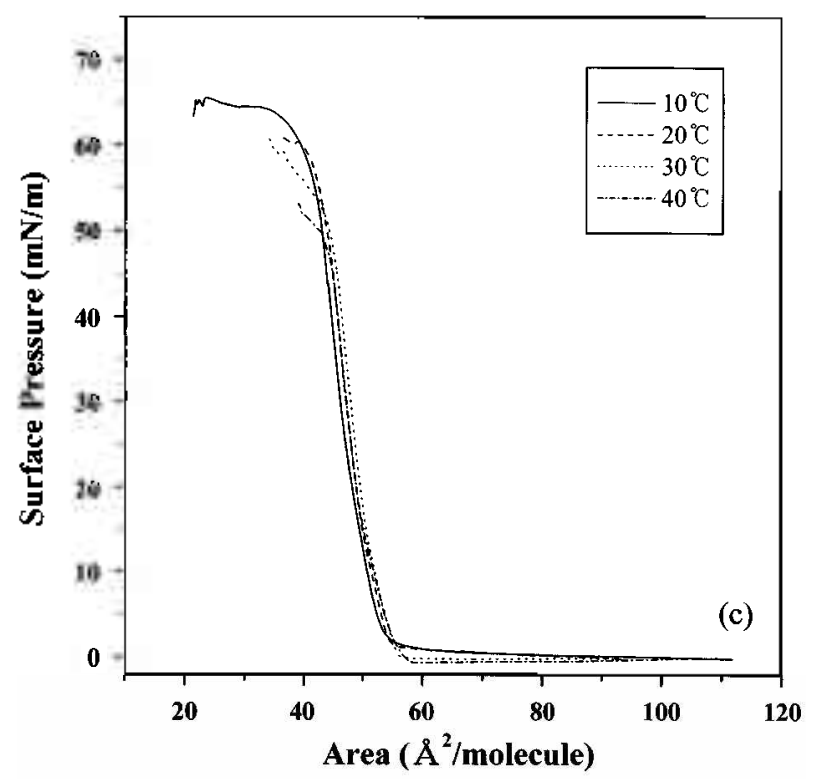

not change dramatically their $\pi$-A isothems by temperature.

Comparing the $\pi$-A isotherms of PC series with computer simulation. The DPPC $(\mathrm{Cl} 16)$ and the DOPC $(\mathrm{C} 8)$ have the same head group, and the alkyl clain length of DPPC $(\mathrm{Cl} 6)$ is twice as large as that of $\mathrm{DOPC}(\mathrm{C} 8)$. There are at least two distinguishable liquid phases at the air-water interface. The first was called liquid expanded having rather lugh compressibility and the second was called liquid condensed phase of a low compressibility as discussed in reference 23 . Their $\pi$-A isotherms of surface pressure and compressibility in Figure 5(a) show that DOPC (C8) has smooth curve with one phase transition at $66.44 \mathrm{~A}^{2} /$ molecule, but as shown Figure 5(b). DPPC(Cl6) has three phase transition at 80.49 $\mathrm{A}^{2} /$ molecule. $48.29 \mathrm{~A}^{2} /$ molecule. $40.58 \mathrm{~A}^{2} /$ molecule. These experiments reveal that $\mathrm{DPPC}(\mathrm{C} 16)$ has liquid expandedliquid condensed coexistence region by compression.
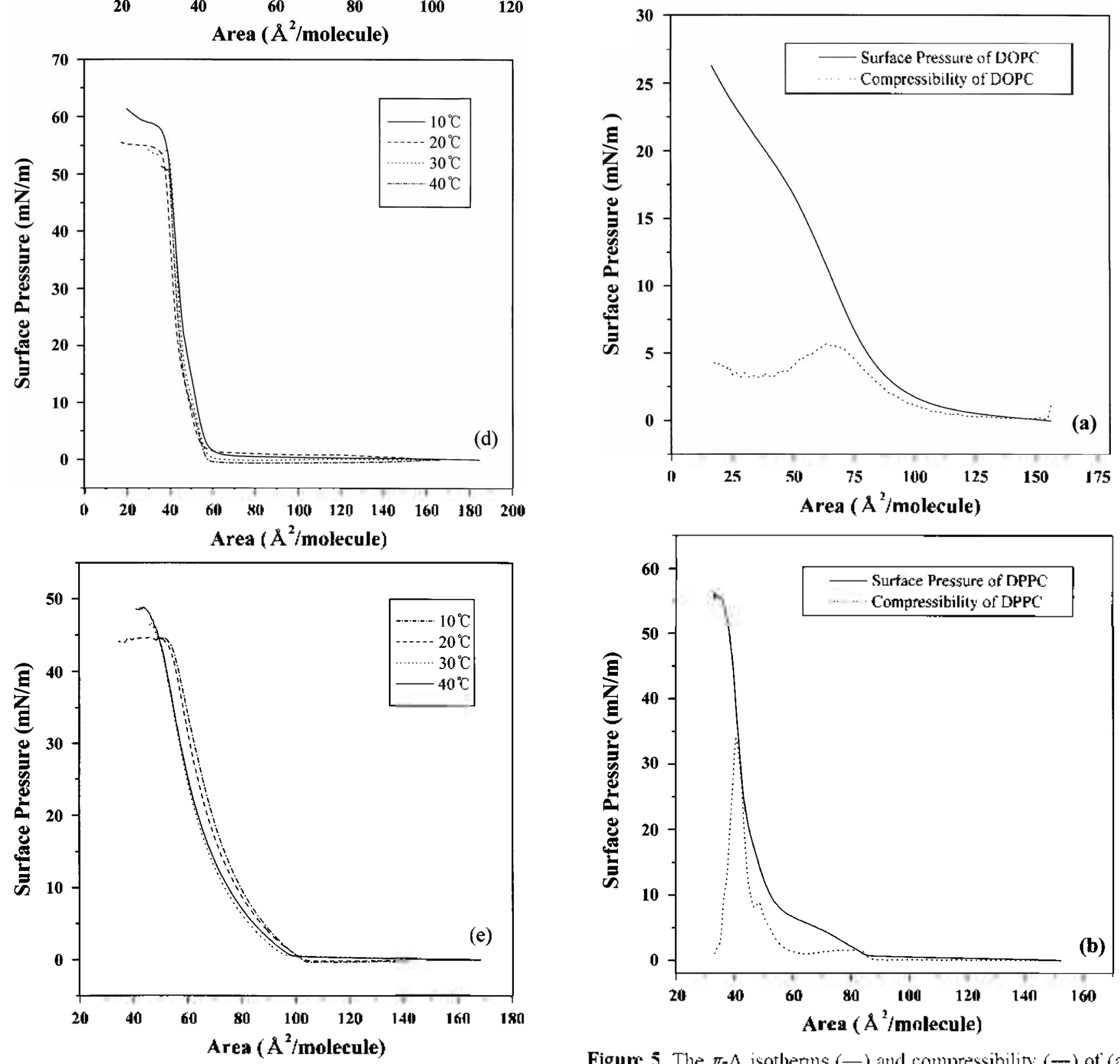

Figure 4. Contimued.

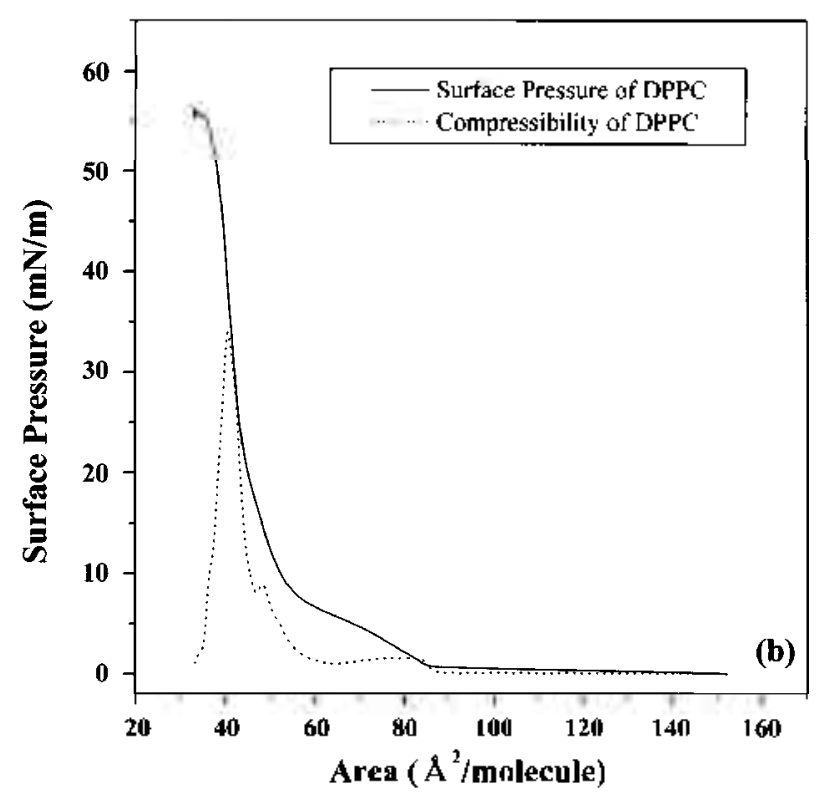

Figure 5 . The $\pi-\wedge$ isothents (-) and compressibility (-) of (a) DOPC (C $)$ and (b) DPPC (C 16$)$ at 20 " $\mathrm{C}$. 

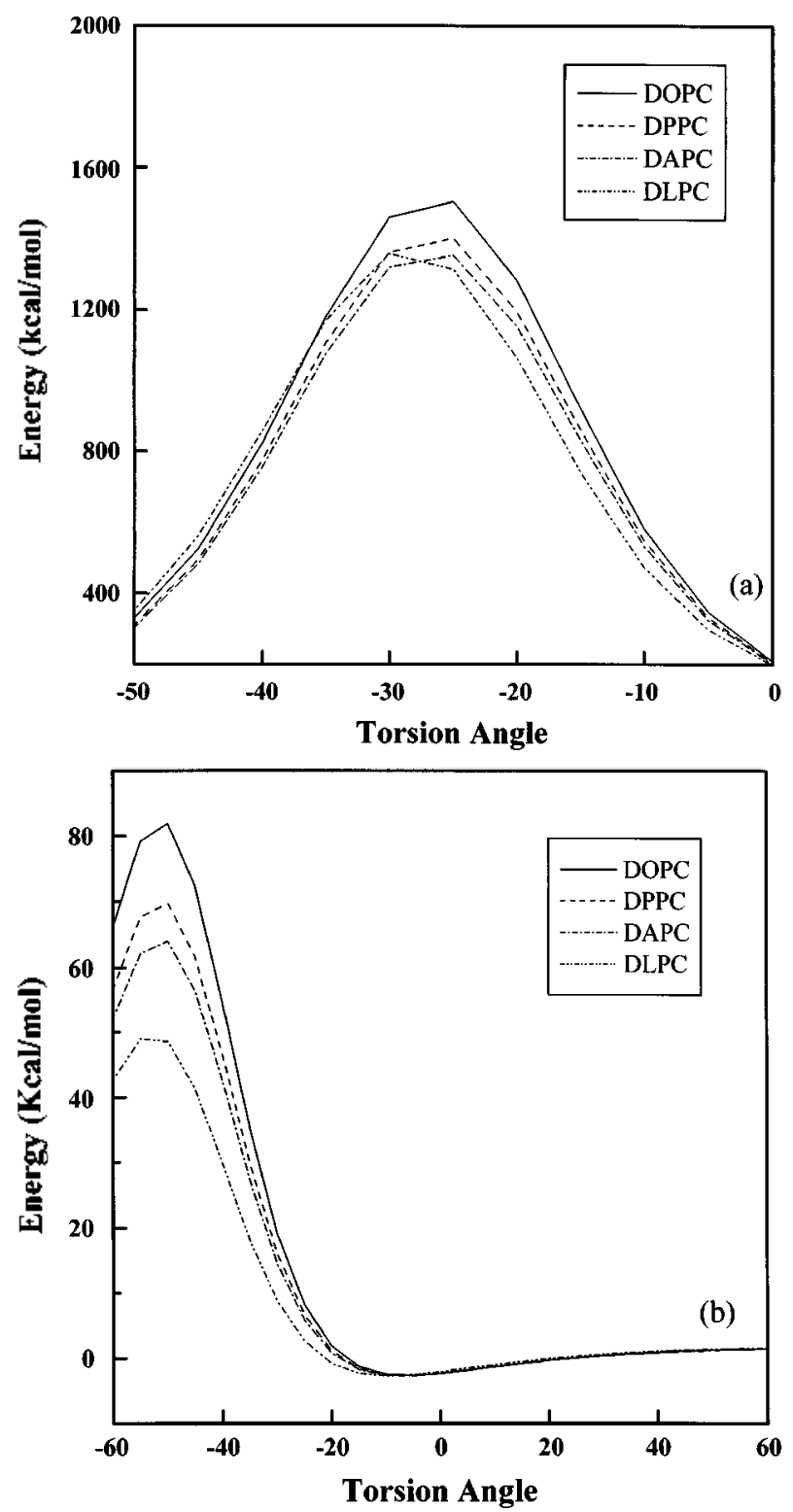

Figure 6. (a) Confonmational energy curves of DOPC(C8), DPPC (C 16), DAPC (C20), and DLPC ( 24$)$, (b) Inleraction encrgy wrie betwen two $(\beta, \gamma)$ chains of DOPC(C8), DPPC (C.16), $\mathrm{DAPC}(\mathrm{C} 20)$, and DI, PC $(\mathrm{C} 24)$ bs CHARMM lipid force tield.

The increased order as a smaller surface can result from changes in the internal conformation of the lipid by the chain dihedral distributions or by the overall molecular orientation ${ }^{=+}$To separate these two effects, the potential energies for rotation about the $\alpha \mathrm{Cl}-\gamma \mathrm{O} 1-\gamma \mathrm{Cl}-\gamma \mathrm{C} 2$ (as in Figure 1) dihedral angles of $\mathrm{DOPC}(\mathrm{C} 8)$. $\mathrm{DPPC}(\mathrm{C} 16)$. DAPC $(\mathrm{C} 20)$. and $\mathrm{DLPC}(\mathrm{C} 24)$ molecules were calculated along 10 degree rotation. The $\beta$ chain was anchored and fixed on $\alpha \mathrm{Cl}$ carbon and the $\gamma$ chain was rotated clockwise through $180^{\circ}$ to $-180^{\circ}$. The lipid force field of all-hydrogen atomic model with CHARMM was used. In the case of DOPC(C8), the region that has above $200 \mathrm{kcal} / \mathrm{mol}$ conformational energy difference is from $-55^{\circ}$ to $-0^{\circ}$ and maximum conformational energ: difference is $1+98.09 \mathrm{kcal} / \mathrm{mol}$. For DPPC(C 16). however. the region that has above $200 \mathrm{kcal} / \mathrm{mol}$ conformational energy difference is from $-50^{\circ}$ to $-5^{\circ}$ and maximum conformational energy difference is $1391.36 \mathrm{kcal} / \mathrm{mol}$. Therefore the shorter alkỵl chains length, the broader high conformational energy: region as shown in Figure 6(a). These calculations tell us that flexibility of molecule itself have increased tendency with alkyl chain length and consist with result of Figure 5. In Figure 5 (a). we have seen the smooth plase transition of DOPC $(\mathrm{C} 8)$ and the stiff phase transition of DPPC $(\mathrm{Cl} 16)$ at Figure 5(b). The high peaks of compressibility cure of DPPC(Cl6), in Figure 5(b), coincide with narrow conformation energy region in Figure 6(a), and it could explain that if the molecule has wide relatively low conformational energy region. molecule has a lot chance to phise transition and then compressibility value is large. And in comparison with $\mathrm{DPPC}(\mathrm{Cl6})$, low cure of compressibility of DOPC $(\mathrm{C} 8)$, in Figure 5(a). coincides with wide relatively ligh conformational energy region.

We also calculated the hydrocarbon interaction energ: between the $\beta$ chain and the $\gamma$ chain during the rotation. The interaction energy function is partitioned as

$$
E_{J}=\sum_{i, j>1}\left(\frac{q_{i} q_{j}}{4 \pi \varepsilon_{i 1} r_{i j}}\right)+\sum_{i, j>1}\left(\frac{A_{i j}}{r_{i j}^{12}}-\frac{B_{i j}}{r_{i j}^{6}}\right)
$$

Where first tem is electrostatic energy: $q q q$ is atomic charges of each atom, \& is dielectric constant. $r_{i j}$ is interatomic distance and second term is van der Walls energy: $t_{p}$ and $B_{i j}$ are derived from the atomic polarizabilities and the effective number of outer shell electrons. respectively. ${ }^{2.5}$

In Figure 6(b). the interaction energy of DOPC(C8) has from $-2.60 \mathrm{kcal} / \mathrm{mol}$ to $81.8+\mathrm{kcal} / \mathrm{mol}$ and that of DPPC (C16) has from $-2.62 \mathrm{kcal} / \mathrm{mol}$ to $69.71 \mathrm{kcal} / \mathrm{mol}$, where the maximum interaction energy region is $-5^{\circ}$. These results support that the longer alkyl chain length. the more increased intermolecular interaction. So the formed aggregates of the molecule are rigid becalse of the hydrophobic interaction between chains. From the above results. Lipid molecules have lower conformational energy in liquid-expanded region, but in liquid-condensed region. lipid molecules have high conformational energy and stabilize molecule chain interaction. Because the longer alkyl chains have high flexible and good interaction of chains than those of shorter alkỵl chain and the molecules having longer alkyl chain have the tendency of stiff phase transition.

Comparing the $\pi$-A isotherms of saturated PC and unsaturated PC. Figure 4(e) shows the $\pi$-A isotherms of POPC. one of unsaturated phosphatidy lcholine phospholipids. $\mathrm{DPPC}(\mathrm{Cl}$ 6) and POPC have the same hydrocarbon numbers. but POPC has cis-double bond in one of alkyl chains on $\gamma$ chain. The phase transition between the liquid expanded (LE) and liquid condensed (LC) states of DPPC(Cl6) is prominent in the $\pi$-A isotherm, but there is no phase transition (plateau region) in that of POPC during compression in Figure $4(\mathrm{e})$. DPPC $(\mathrm{Cl} 6)$ has internal dihedral transition but that of POPC is limited because one cis-double bond disturbs the motion of another alkyl chain. To reveal the relationship of $\pi$-A isotherms between POPC and 
Table 1. The cis-trans conlonmational energ dillerences of LPPC and POPC. The unit is $\mathrm{kcal} / \mathrm{mol}$

\begin{tabular}{cccc}
\hline & cis energy & trans energy & $\Delta \mathrm{li}$ \\
\hline DPPC & 11.800 & 5.054 & 6.746 \\
POPC & 65.242 & 3.184 & 62.058 \\
\hline
\end{tabular}

DPPC(C 16). we calculated cis-trans confommational energ: of the molecules. The cis-trans confonmational energ: difference of POPC has $62.058 \mathrm{kcal} / \mathrm{mol}$ whereas that of DPPC $(\mathrm{Cl}$ ) has $6.746 \mathrm{kal} / \mathrm{mol}$. In general. molecules had double bond have high conformational energy barrier. The $\pi$-A isothem of POPC doesn't show special phase transition because the confonmational energy barrier of $\mathrm{POPC}$ is higher than that of $\mathrm{DPPC}(\mathrm{Cl}$ 6). so conformational change is limited in comparison with $\mathrm{DPPC}(\mathrm{Cl} 16)$. The effect of temperature on POPC is negligible because one alknl chain with double bond interrupts motion of another alkyl chain and the thermal motion of molecules could be restricted. as in Figure $+(\mathrm{e})$. These results are summarized on Table 1.

\section{Conclu sion}

At the air/water interface. the surface pressure is influenced by two interfaces: hydrophobic region of molecules/air interface and lydrophilic parts of molecules/aqueous subphase interface. By increasing the length of alkyl chain in PCs, the surface pressure is influenced mainly by hydrophobicity, that is confirmed by curve shape and on-set value of $\pi$-A isotherms. tendency of monolayer thickness, and computer simulations. The orientations of alkrl chains at the air/water interface are closely connected with the rigidity of the monolayers. The orientation of the PCs $(\mathrm{C} 20 . \mathrm{C} 24)$ is rather horizontal with respect to the surface normal and this explains that the PCs (C20, C24) are arranged vertically at the air/water surface of large Am, and it is confirmed by ellipsometry data. Also, the temperature dependence of a series of PCs shows that. by increasing temperature, the surface pressure decreases because the longer the alkyl chain length the larger the hydrophobic interaction in surface pressure.

Comparing the $\pi$-A isotherms of saturated $\mathrm{PC}$ and of unsaturated $P C$. the transition between the liquid expanded (LE) and liquid condensed (LC) states of DPPC $(\mathrm{Cl}$ ) is prominent in the $\pi$-A isotherm. but there is no transition (plateau region) in that of $\mathrm{POPC}$ during compression. The alkyl chain of POPC having one cis double bond which disturbs the motion of another alkyl chain. so that conformational change is limited. This is confimed by showing the energy difference of cis-trans transition of POPC and $\mathrm{DPPC}(\mathrm{Cl} 6)$ by computer simulation.

Acknowledgement. This work was supported by the research fund from the Hanyang University in 2001.

\section{References}

1. Weideman. G.: Vollhardt. D, Thin Solid Fihm 1995. 264. 94.

2. Van Bunt. J. Biotechologe 1985, 3. 209.

3. Haddon. R. C.: Lamola. A. A. Proc. Wt. Acda. Sci. LS.ł 1985. 82. 1874

4. Phillips, M. C.: Chapman. D. Biochim, Biophss. Icta 1968. 23, 301 .

5. Colacicen, G. J. Colloid Interface. Sci. 1968, 29.345.

6. Colaciceo. G.: Ann. N. Y. Acad. Sci, 1972. 195. 224.

7. Colaciceo. Ci.: Buckelen. Ar: Ir:. Scarpello. E. W. J. Colloid. Inferface. Sci. 1974. f6. 147.

8. I.osche, M.: IIelm, C.: Matles, HI. D.: Mohwald. II. Thin Solid Films 1985, 133, 51

9. Ohamura, F.:. Uncmura. I.: Takenaka. T. Biochim. Biophls. Acto 1985. 812.139

10. Tchorelol. D.: Gulik. A.: Denizot. B.: Puisieux. F. Chem. Whus. Lipids. 1991. 109. 151 .

11. Iliticda, Y. F.: Rasticld, G. W. Lomgnwir 1992. 82.197.

12. Jyoti, A.: Prokop, R. M.: Neumantı. A. W. Colloids Sufaces B: Biointerfaces 1997. 8. 115.

13. Kim. H. J: Yoo. J. S.: Kim. M. S. Bull. Sonem Chem. Soc. 1997. 18.874.

14. Balazs. D. É: Schimit. P. L.: Szuhaj. B. F. J. Am. Oil Chem. Soc. 1996, 193.7.3.

15. Meulenacr, B. D.: Mecren. P. V.: Vanderdeclen, I.: Bactt. I. . J. . Im OHl (hem. Soc. $1995.1973,72$.

16. lausk. R. J. M.: Karmiggelt. J.: Oudshoorn. C. Biophys. Chem. 1974. 1. 175.

17. De Hass. G. H.: Bonsen. P' P. M: P'ieterson. W. A. Biochim. Biophys .lcta 1971. 239. 252.

18. Mason, C. D.: Rand, T. G.: Anthes, M. Toxicology and lpplied Phawhacologv 2001. 172. 21.

19. Avery. M. E.: Mead. J. J. Dis. Child. 1959. 51.517.

20. Nag. K.: Perez-Gil. I.: Crz. A.: Rich. N. H. Biophys. J. 1996. 71. 1356.

21. Thomas, I. K. ICS .1 fonograph NO 181: Amcrican Chemical Society: Washington, DC, 1884.

22. Kalyanasundaran. K.: Thomas. J. K. J .1m. Chem Soc. 1977. 99. 2039 .

23. Gaines. G. L. Insohble Honoloners Lignid-Gas Inferfaces: Interscience: New York. 1966.

24. Feller', S. F.: Venable, R. M.: Pastor. R. W. Iangmin 1997, /3. 6555 .

25. Feller, S. Г.: Yin, D.: Pastor', R. W.: Mackerell, Jr'., A. D. Biophys: J. 1997. 73.2269 . 